\title{
Examining the profile of high-potency cannabis and its association with severity of cannabis dependence
}

\author{
T. P. Freeman ${ }^{1 *}$ and A. R. Winstock ${ }^{2}$ \\ ${ }^{1}$ Clinical Psychopharmacology Unit, University College London, London, UK \\ ${ }^{2}$ Institute of Psychiatry, King's College London, Camberwell, UK
}

Background. Cannabis use is decreasing in England and Wales, while demand for cannabis treatment in addiction services continues to rise. This could be partly due to an increased availability of high-potency cannabis.

\begin{abstract}
Method. Adults residing in the UK were questioned about their drug use, including three types of cannabis (high potency: skunk; low potency: other grass, resin). Cannabis types were profiled and examined for possible associations between frequency of use and (i) cannabis dependence, (ii) cannabis-related concerns.

Results. Frequent use of high-potency cannabis predicted a greater severity of dependence [days of skunk use per month: $b=0.254,95 \%$ confidence interval (CI) $0.161-0.357, p<0.001]$ and this effect became stronger as age decreased $(b=-0.006,95 \% \mathrm{CI}-0.010$ to $-0.002, p=0.004)$. By contrast, use of low-potency cannabis was not associated with dependence (days of other grass use per month: $b=0.020,95 \%$ CI -0.029 to $0.070, p=0.436$; days of resin use per month: $b=0.025,95 \%$ CI -0.019 to $0.067, p=0.245$ ). Frequency of cannabis use (all types) did not predict severity of cannabis-related concerns. High-potency cannabis was clearly distinct from low-potency varieties by its marked effects on memory and paranoia. It also produced the best high, was preferred, and most available.
\end{abstract}

Conclusions. High-potency cannabis use is associated with an increased severity of dependence, especially in young people. Its profile is strongly defined by negative effects (memory, paranoia), but also positive characteristics (best high, preferred type), which may be important when considering clinical or public health interventions focusing on cannabis potency.

Received 9 January 2015; Revised 18 May 2015; Accepted 19 May 2015; First published online 27 July 2015

Key words: Addiction, cannabidiol, cannabis, delta-9-tetrahydrocannabinol, dependence, marijuana.

\section{Introduction}

There is huge variation in the types of cannabis (marijuana) available worldwide (UNODC, 2014). This is evident in illicit markets and also legal ones. For example, an unprecedented number of cannabis products and preparations are now available in Colorado (Coombes, 2014). By contrast, sales in Uruguay may be restricted to five strains only, with an upper limit on potency (Coombes, 2014).

Cannabis potency is typically judged according to concentrations of delta-9-tetrahydrocannabinol (THC), the primary psychoactive constituent in cannabis. However, the cannabis plant contains many other cannabinoids, most notably cannabidiol (CBD). These other cannabinoids (and possibly other plant chemicals known as terpenoids; Russo, 2011) contribute to potency by moderating the effects of THC. For example,

\footnotetext{
* Address for correspondence: Dr T. Freeman, Clinical Psychopharmacology Unit, University College London, Gower St, London, WC1E 6BT, UK.

(Email: tom.freeman@ucl.ac.uk)
}

CBD can block or dampen the effects of THC across a range of domains (Zuardi et al. 1982; Morgan \& Curran, 2008; Morgan et al. 2010a,b, 2012; Englund et al. 2012; Hindocha et al. 2015). These findings concur with users' ratings of cannabis potency, which are positively correlated with THC and negatively with CBD (Freeman et al. 2014).

Natural cannabinoid synthesis (and therefore cannabis potency) is influenced by a range of factors including genetics, growing conditions (especially light), harvest time, the part of the plant used, drying, storing and processing (Potter, 2014). Most products can be classified into three broad types: (1) high potency - indoorgrown floral material of unfertilized plants, whereby energy is diverted from seed production to cannabinoid synthesis ('skunk', 'sinsemilla'; meaning 'without seeds'); (2) low potency - outdoor-grown imported floral material ('herbal', ' 'grass', 'weed'); and (3) compressed blocks of plant matter ('resin', 'hashish'). Skunk is characterized by the highest THC content $(\sim 15 \%)$, followed by imported herbal/grass $(\sim 9 \%)$ and then resin $(\sim 5 \%)$, although there is considerable variation within these categories (Hardwick \& King, 2008). Concentrations of CBD are

This is an Open Access article, distributed under the terms of the Creative Commons Attribution licence (http://creativecommons.org/licenses/by/ $3.0 /)$, which permits unrestricted re-use, distribution, and reproduction in any medium, provided the original work is properly cited. 
typically low or completely absent in skunk and other herbal/grass preparations. By contrast, resin/hashish (and presumably landrace populations of cannabis plants) typically contain comparable quantities of THC and CBD (Potter et al. 2008). Thus, indoor-grown floral cannabis (skunk) is the clearly most potent type of cannabis (followed by imported herbal/grass, and then resin/hashish), and might be expected to be most strongly associated with any adverse effects of cannabis use. This is currently an under-researched area, although preliminary evidence suggests that regular use of high-potency (skunk) cannabis is predictive of first-episode psychosis (Di Forti et al. 2009) and an earlier onset of psychosis, particularly among daily users (Di Forti et al. 2013). By contrast, resin/hashish is not linked to an increased risk of psychosis, even among daily users (Di Forti et al. 2015).

It is estimated that $3.8 \%$ of the world's population used cannabis in the last year (UNODC, 2014) and this figure has remained relatively stable in the last decade. In England and Wales, however, prevalence of last year use dropped from $10.7 \%$ to $6.6 \%$ between $2002 / 2003$ and 2013/2014 (Home Office, 2014). Despite this overall reduction in use, demand for cannabis in addictiontreatment services has continued to rise across the same time period: between 2005/2006 and 2013/2014 new admissions for cannabis rose from 7579 to 11821 in adults (NDTMS, 2014) and from 9043 to 13659 among under 18s (NDTMS, 2015). There are now more first-time clients for cannabis treatment in Europe than any other illicit drug (EMCDDA, 2014).

One possible explanation for these trends is an increase in cannabis potency. Data from cannabis seizures have documented rising THC concentrations in the UK. This is predominantly due to an increase in the availability of high-potency, indoor-grown (skunk) cannabis which made up $15 \%$ of police seizures in 1999-2002 (King et al. 2004), 55\% in 2004-2005 (Potter et al. 2008) and 81\% in 2007-2008 (Hardwick \& King, 2008). These trends are matched by seizure data across Europe (EMCDDA, 2014). Cannabis users titrate (use less) as THC rises but only partially (Freeman et al. 2014; van der Pol et al. 2014) and not in response to CBD (Freeman et al. 2014). It is therefore possible that repeated exposure to high THC concentrations, and little if any CBD, may have increased users' dependence on cannabis.

In this study, we recorded detailed information on use of and experiences with different types of cannabis through an online drug survey. This approach made it possible to recruit a large sample who had used all of three different cannabis types (skunk, other grass, resin) within the last 12 months, permitting withinsubject comparison of cannabis types. We aimed to test the hypothesis that severity of dependence, and concerns about cannabis use, are more strongly associated with use of high-potency than low-potency cannabis. Additionally, we explored users' experiences of each type of cannabis in relation to effects on memory, paranoia, quality of high, preference, value for money and availability.

\section{Method \\ Design and participants}

An online cross-sectional drugs survey, The Global Drug Survey, was conducted in November 2009 as reported elsewhere (Winstock et al. 2011). All participants confirmed that they were aged $\geqslant 18$ years, and consented for the information they gave to be analysed. Ethical approval was received from the joint South London and Maudsley and Institute of Psychiatry National Health Service (NHS) Research Ethics Committee.

\section{Assessments}

The survey collected demographic data and detailed information on use of and experience with a number of substances. The data presented and analysed in this report is the UK data only; cases living in England, Scotland, Wales, and Northern Ireland form the UK dataset. Rather than recording information on cannabis use generally (e.g. age when cannabis was first used, days of cannabis use per month), separate questions were provided for (1) resin, (2) skunk grass (hereafter 'skunk'), (3) grass other (hereafter 'other grass'). This enabled each type to be rated as a separate drug. The following information was collected for each type of cannabis:

\section{Comparing use of cannabis types}

Used in the last 12 months? (yes/no).

Days used in the last month.

How long does $1 / 8$ th last you (in days). $\dagger$

How many joints from $1 / 8$ th?

\section{Profiling cannabis types}

Respondents who had used all three cannabis types in the last 12 months were asked to choose one type for each of the following questions:

Which gives the best high?

Which is the best value for money?

Which is most likely to get you paranoid?

+ One-eighth of an ounce ( $3.5 \mathrm{~g})$, an amount typically sold in the UK. 
Which is most likely to affect your memory? Which is your preferred type?

Which is most available?

\section{Route of administration}

Respondents were asked whether they had ever used cannabis using the following methods: smoked in joint without tobacco, smoked in joint with tobacco, smoked in bong/water pipe without tobacco, smoked in bong/water pipe with tobacco, eaten/cooked, used in a vaporizer.

\section{Severity of dependence and cannabis-related concerns}

These questions were assessed with reference to cannabis use generally. Cannabis dependence was assessed using the Severity of Dependence Scale (SDS; Gossop et al. 1995), which was adapted for the survey with abbreviated response options as shown below. Scores can range from 0 to 15 , and scores $\geqslant 3$ on the original scale indicate dependence on cannabis (Swift et al. 1998).

(1) Do you ever think your use of cannabis is out of control? [never (0); sometimes (1); often (2); always (3)].

(2) Does the prospect of missing a smoke make you very anxious or worried? [never (0); sometimes (1); often (2); always (3)].

(3) Do you worry about your use of cannabis? [never (0); sometimes (1); often (2); always (3)].

(4) Do you wish you could stop? [never (0); sometimes (1); often (2); always (3)].

(5) How difficult would you find it to stop or go without? [not difficult (0); quite difficult (1); very difficult (2); impossible (3)].

Additionally, the following questions were asked (yes/no):

Have you ever discussed your cannabis use with a healthcare professional?

Have you ever thought you might need treatment for your cannabis use?

Have you ever sought treatment for cannabis use? Have you ever tried to stop smoking cannabis?

Participants were also asked about a range of concerns relating to their cannabis use:

We are interested in what worries you about smoking cannabis. Please rate the following possible health-related consequences of smoking cannabis on a scale of $1-10$, where $1=$ no concern for you and $10=$ big concern for you: cancer, chronic lung disease, effect on memory, effect on mental health, legal issues, effect on relationships, effect on work or study, lack of motivation.

\section{Statistical analysis}

Repeated-measures ANOVA models were used to compare each cannabis type for indices of use. Post-hoc $t$ tests were corrected locally using the Bonferroni method. $\chi^{2}$ tests were used for comparing the profile of cannabis types. Current age was split into quartiles $(<21,21-22$, 23-27 and >27 years) for analysis of first use, and profile of effects. Pearson correlational analyses were used to establish associations between cannabis use variables and SDS scores. Multiple regression was used to predict severity of cannabis dependence and cannabis-related concerns from indices of cannabis use. Analysis of gender was coded as female $=1$, male $=2$, and age was entered as a continuous variable For all regression models, bias-corrected accelerated 95\% confidence intervals (CIs) were estimated using 10000 boostrapping samples.

\section{Results}

\section{Demographics}

Data were available for 2514 respondents. In the last year, prevalence of use was $72.5 \%$ for skunk, $68.6 \%$ for other grass, and $58.7 \%$ for resin cannabis preparations. Thirty-seven per cent (929 respondents) had used all three cannabis preparations in the last year; all further analyses were conducted in this sample. These participants had a mean age of 24.25 (s.D.=6.86) years and $70.2 \%$ were male. Routes of administration (ever used/most common use) were as follows: smoked in joint with tobacco $(98.9 \% / 85.2 \%)$, smoked in joint without tobacco $(75.5 \% / 5.5 \%)$, smoked in bong/water pipe with tobacco $(69.6 \% / 3.3 \%)$, smoked in bong/ water pipe without tobacco $(85.2 \% / 4.5 \%)$, eaten/ cooked $(80.1 \% / 1.1 \%)$, used in a vaporizer $(36.8 \% / 0.4 \%)$.

\section{Comparing use of cannabis types (Table 1)}

Participants reported differences in the number of days they had used each type of cannabis in the last month $\left(F_{2,761}=38.332, p<0.001, \eta_{\mathrm{p}}^{2}=0.087\right)$. Skunk was used for more days than other grass $(p<0.001)$ and resin $(p<0.001)$, while other grass was used for more days than resin $(p<0.001)$. No differences were found for the number of days to smoke $1 / 8$ th $\left(F_{2,895}=1.655\right.$, $\left.p=0.197, \eta_{\mathrm{p}}^{2}=0.003\right)$. Differences emerged for the number of joints made out of $1 / 8$ th $\left(F_{2,893}=62.710, p<0.001\right.$, $\left.\eta_{\mathrm{p}}^{2}=0.108\right)$, reflecting a larger number of joints made from resin compared to skunk $(p<0.001)$ or other grass $(p<0.001)$; a similar number of joints were made for skunk and other grass $(p=0.078)$. There were also differences in age of first use $\left(F_{2,1432}=41.059, p<0.001\right.$, $\left.\eta_{p}^{2}=0.043\right)$; resin was used earlier than skunk $(p<0.001)$ 
Table 1. Comparing use of three cannanbis types

\begin{tabular}{llll}
\hline & Skunk & Other grass & Resin \\
\hline $\begin{array}{l}\text { Days used in the last } \\
\text { month }^{\mathrm{a}}\end{array}$ & $14.05(10.68)$ & $11.46(10.43)$ & $9.45(9.90)$ \\
$\begin{array}{l}\text { Days taken to } \\
\text { smoke 3.5 g }\end{array}$ & $8.55(29.28)$ & $7.31(24.49)$ & $8.14(19.80)$ \\
$\begin{array}{c}\text { Number of joints } \\
\text { made out of 3.5 g }\end{array}$ & $7.93(5.12)$ & $7.63(4.87)$ & $9.41(5.70)$ \\
$\begin{array}{c}\text { Age first used } \\
\text { a }\end{array}$ & $15.90(3.70)$ & $15.38(2.55)$ & $15.18(2.67)$ \\
\hline
\end{tabular}

Values given are mean (s.D.) scores.

${ }^{a}$ Difference across cannabis types at $p<0.001$.

and other grass ( $p=0.002)$; while other grass was used earlier than skunk $(p<0.001)$.

The later age of skunk onset might be attributable to its low availability at the time when this sample first tried cannabis (e.g. 15\% prevalence in 1999-2002; King et al. 2004). We explored this possibility by adding a between-subject factor of current age, split into quartiles, into the model (see Fig. 1). This revealed a cannabis type $\times$ age interaction $\left(F_{5,1468}=29.456, p<0.001, \eta_{\mathrm{p}}^{2}=0.089\right)$ as well as effects of cannabis type $\left(F_{2,1468}=53.598, p<0.001\right.$, $\left.\eta_{\mathrm{p}}^{2}=0.056\right)$ and age $\left(F_{3,900}=42.331, p<0.001, \eta_{\mathrm{p}}^{2}=0.124\right)$. Post-hoc tests showed that in young people (under 21's and 21- to 22-year-olds), all three types of cannabis were first tried at similar ages (all $p^{\prime} s>0.06$ ). By contrast, 23to 27-year-olds had tried resin earlier than other grass $(p<0.001)$ and skunk $(p=0.010)$, which were both tried at an equivalent age $(p=1.000)$. In the over 27 's, there was a marked delay in first trying skunk relative to other grass $(2.00$ years, $p<0.001)$ and resin $(2.42$ years, $p<0.001)$, and resin was again tried earliest ( $p=0.002$ compared to other grass). These data are consistent with a shift in the relative availability of resin and skunk over time, alongside a tendency for younger people to try cannabis at an earlier age.

\section{Profiling cannabis types (Fig. 2)}

Ratings differed across the three cannabis types for 'best high' $\left(\chi_{2}^{2}=539.919, p<0.001\right)$, 'value for money' $\left(\chi_{2}^{2}=126.788, p<0.001\right)$, 'most likely to get you paranoid' $\left(\chi_{2}^{2}=719.880, p<0.001\right)$, 'most likely to affect your memory' $\left(\chi_{2}^{2}=838.049, p<0.001\right)$, 'preferred type' $\left(\chi_{2}^{2}=246.739, p<0.001\right)$, and 'most available' $\left(\chi_{2}^{2}=\right.$ 360.622, $p<0.001$ ). As shown in Fig. 1, skunk scored the highest for 'best high', 'most likely to get you paranoid', 'most likely to affect your memory', 'preferred type', 'most available'. Among these, resin scored above other grass for 'best high' $\left(\chi_{1}^{2}=7.879, p=0.005\right)$, 'most likely to get you paranoid' $\left(\chi_{1}^{2}=18.447, p<\right.$ $0.001)$ and 'most likely to affect your memory' $\left(\chi_{1}^{2}=\right.$
44.445, $p<0.001)$. By contrast, resin scored lower than other grass for 'most available' $\left(\chi_{1}^{2}=30.201, p<0.001\right)$ and they both scored equally for 'preferred type' $\left(\chi_{1}^{2}=1.011, p=0.315\right)$. In terms of 'value for money', resin was rated the highest, above skunk $\left(\chi_{1}^{2}=15.334\right.$, $p<0.001)$, which in turn scored higher than other grass $\left(\chi_{1}^{2}=58.911, p<0.001\right)$. The same pattern of results was found when the sample was split according to gender or age quartiles.

\section{Severity of dependence and cannabis-related concerns}

Exploratory correlations were conducted between SDS scores and all 12 indices of use (for skunk, other grass and resin: age of first use, days used in the last month, days taken to smoke $1 / 8$ th, number of joints from $1 / 8$ th). For days used in the last month, Pearson's $r$ values reflected a medium-large effect size for skunk $(r=0.432)$ and small-medium effect sizes for other grass $(r=0.290)$ and resin $(r=0.247)$. For all other indices of use, effect sizes were small (all $r^{\prime} \mathrm{s} \leqslant 0.155$ ). Scores for severity of dependence (and individual concerns about cannabis) were therefore regressed onto days of skunk, other grass, and resin use in the last month.

Four hundred and three respondents had used each of the three cannabis types at least once in the last month; the following analyses were conducted in those individuals. Within their lifetime, $23.0 \%$ had discussed their cannabis use with a healthcare professional, $17.8 \%$ thought they might need treatment for their cannabis use, $5.3 \%$ had sought treatment for cannabis use, and $47.4 \%$ had tried to stop smoking cannabis. On the SDS, they had a mean score of 2.82 (S.D. $=3.29)$. Scores ranged from 0 to 14 (out of a maximum of 15) and quartiles were $0.00,2.00$, and 4.50 . When classified using the cut-off of $\geqslant 3$ (Swift et al. 1998), 38\% of the sample currently met criteria for cannabis dependence.

As shown in Table 2, frequency of cannabis use in the last month predicted severity of dependence, accounting for $14.4 \%$ of the variance in these scores. This was driven by skunk; no associations emerged for other grass or resin. We additionally investigated whether this effect was moderated by gender or age. Adding gender and age into the model (step 2) did not account for additional variance, but including them as moderators of skunk use (step 3) improved model fit. Removing redundant predictors (step 4) did not result in a loss of variance explained and accounted for a total of $15.5 \%$. SDS scores increased $(b=0.254,95 \%$ CI $0.161-0.357, p<0.001)$ for each additional day of skunk per month. This relationship became stronger as age decreased $(b=-0.006,95 \% \mathrm{CI}$ -0.010 to $-0.002, p=0.004)$. SDS scores also increased with age $(b=0.081,95 \%$ CI $0.014-0.170, p=0.039)$. 


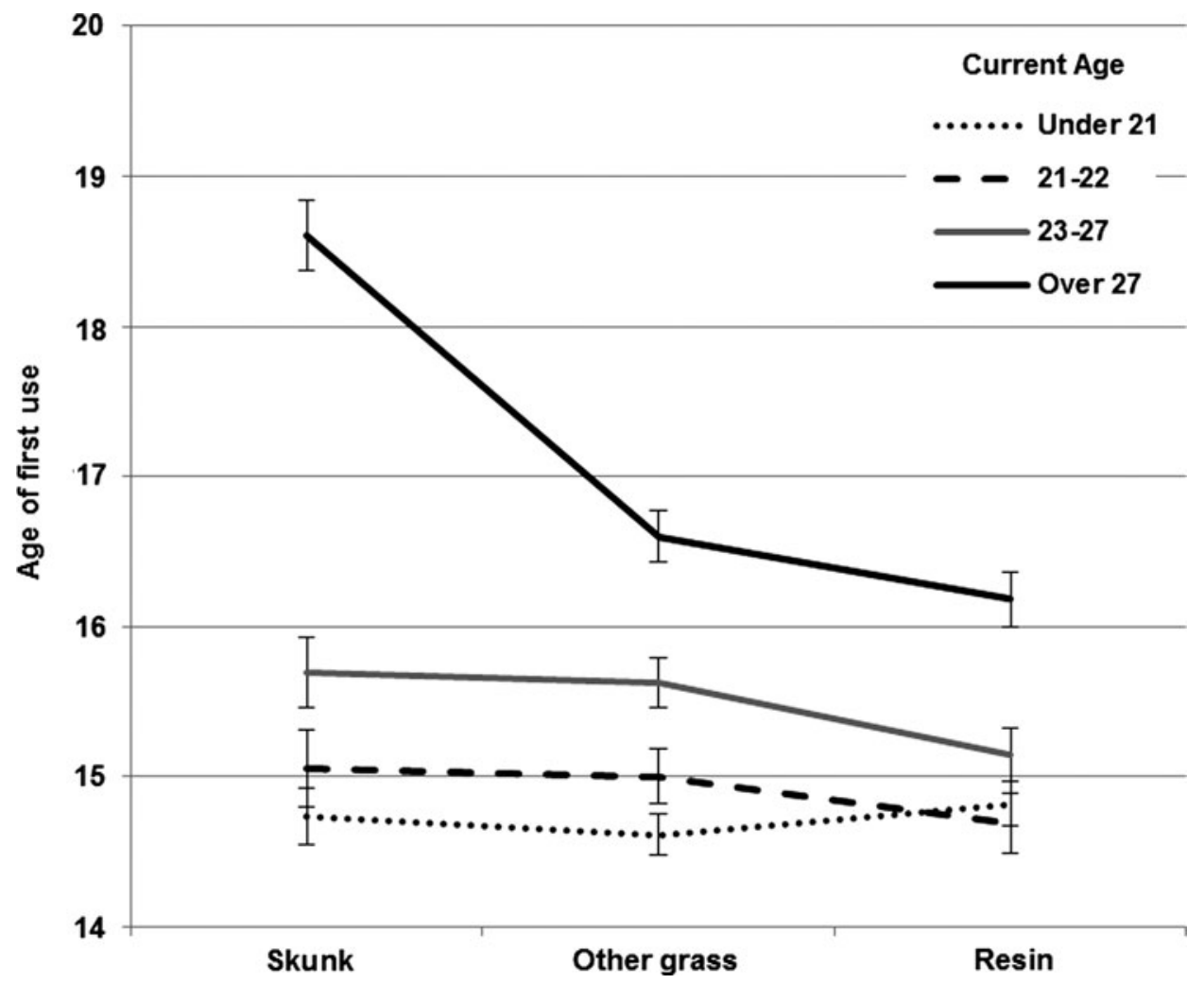

Fig. 1. Current age and first use of cannabis. Young people in the sample (currently under 23) were exposed to all three types of cannabis at similar ages. Older people were exposed to resin earlier than other types of cannabis, and skunk use was markedly delayed in the over 27 's. These results support a shift in the relative availability of resin and skunk over time.

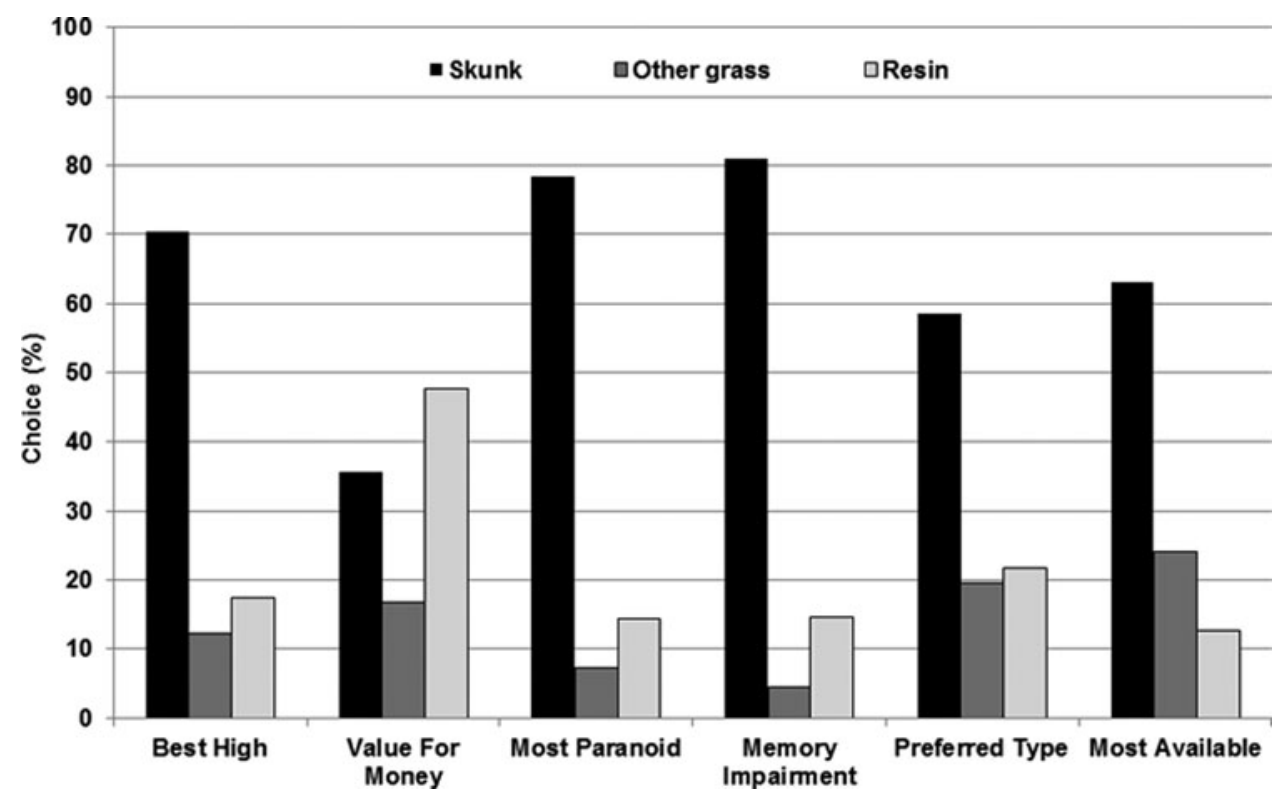

Fig. 2. Characteristics of three cannabis types. Skunk was the predominant choice for all attributes apart from value for money.

Mean (S.D.) scores for cannabis-related concerns about cannabis were as follows (presented in descending order of concerns). Memory: 4.98 (2.87); work or study: 4.58 (2.98); mental health: 4.42 (3.16); motivation:
3.97 (3.50); chronic lung disease: 3.85 (2.76); cancer: 3.70 (2.75); relationships: 3.33 (2.71); legal issues: 3.01 (2.66). Frequency of cannabis use (skunk, other grass, resin) did not predict scores for any of these concerns. 
Table 2. Predicting severity of cannabis dependence from frequency of use

\begin{tabular}{|c|c|c|c|c|}
\hline & \multirow[b]{2}{*}{$b$} & \multicolumn{2}{|l|}{$95 \% \mathrm{CI}$} & \multirow[b]{2}{*}{$p$} \\
\hline & & Lower & Upper & \\
\hline \multicolumn{5}{|l|}{ Step 1} \\
\hline \multicolumn{5}{|c|}{ Total $R^{2}=0.144, p<0.001$} \\
\hline Constant & 1.046 & 0.636 & 1.473 & \\
\hline Skunk & 0.093 & 0.048 & 0.139 & $<0.001$ \\
\hline Other grass & 0.020 & -0.029 & 0.070 & 0.436 \\
\hline Resin & 0.025 & -0.019 & 0.067 & 0.245 \\
\hline \multicolumn{5}{|l|}{ Step 2} \\
\hline \multicolumn{5}{|c|}{$\Delta R^{2}=0.003, p=0.553$} \\
\hline \multicolumn{5}{|c|}{ Total $R^{2}=0.147, p<0.001$} \\
\hline Constant & 1.746 & 0.413 & 2.981 & \\
\hline Skunk & 0.096 & 0.051 & 0.143 & $<0.001$ \\
\hline Other grass & 0.018 & -0.030 & 0.069 & 0.477 \\
\hline Resin & 0.025 & -0.018 & 0.067 & 0.245 \\
\hline Age & -0.003 & -0.046 & 0.050 & 0.905 \\
\hline Gender & -0.380 & -1.064 & 0.317 & 0.268 \\
\hline \multicolumn{5}{|l|}{ Step 3} \\
\hline \multicolumn{5}{|c|}{$\Delta R^{2}=0.023, p=0.005$} \\
\hline \multicolumn{5}{|c|}{ Total $R^{2}=0.170, p<0.001$} \\
\hline Constant & 0.913 & -0.874 & 2.537 & \\
\hline Skunk & 0.146 & 0.018 & 0.278 & 0.024 \\
\hline Other grass & 0.014 & -0.034 & 0.062 & 0.584 \\
\hline Resin & 0.022 & -0.021 & 0.064 & 0.298 \\
\hline Age & 0.078 & 0.012 & 0.156 & 0.037 \\
\hline Gender & -1.030 & -2.142 & 0.094 & 0.058 \\
\hline Age $\times$ skunk & -0.006 & -0.010 & -0.002 & 0.003 \\
\hline Gender $\times$ skunk & 0.052 & -0.019 & 0.121 & 0.160 \\
\hline \multicolumn{5}{|l|}{ Step 4} \\
\hline \multicolumn{5}{|c|}{$\Delta R^{2}=-0.015, p=0.138$} \\
\hline \multicolumn{5}{|c|}{ Total $R^{2}=0.155, p<0.001$} \\
\hline Constant & -0.733 & -2.865 & 0.922 & \\
\hline Skunk & 0.254 & 0.161 & 0.357 & $<0.001$ \\
\hline Age & 0.081 & 0.014 & 0.170 & 0.039 \\
\hline Age $\times$ skunk & -0.006 & -0.010 & -0.002 & 0.004 \\
\hline
\end{tabular}

CI, Confidence interval.

Significant predictor variables are shown in bold.

Days of skunk use, but not other grass or resin, predicted higher Severity of Dependence Scale scores. The relationship between skunk use and severity of dependence became stronger as age decreased.

\section{Discussion}

This study compared the profile of three cannabis types and their associations with cannabis dependence. Our findings clearly show that use of high-potency (skunk) but not low-potency (other grass, resin) cannabis is associated with an increased severity of dependence, especially in young people. Furthermore, the profile of high-potency (skunk) cannabis was marked in terms of negative effects (memory and paranoia) but also positive characteristics (preferred type and best high). It was also rated as the most available type, but was not the best value for money.

The past decade has seen a huge increase in the prevalence of high-potency (skunk-type) cannabis in England and Wales (King et al. 2004; Hardwick \& King, 2008; Potter et al. 2008; Freeman et al. 2014) alongside rising demand for cannabis treatment in addiction services (NDTMS, 2014, 2015). Our findings are consistent with these observations, and are the first to our knowledge reporting a link between cannabis potency and severity of drug dependence. Thus, clinically, it might be useful (and desirable) to encourage skunk users at risk of/experiencing dependence to move to less potent forms of cannabis if they are not motivated to quit.

Younger people were especially vulnerable, displaying a stronger relationship between extent of skunk use and severity of dependence. This is in agreement with observations that more under 18 's seek treatment for cannabis than all adults combined, unlike any other drug (NDTMS, 2014, 2015). Young people in our sample were also exposed to skunk from an earlier age; older adults tried resin first and had not tried skunk until an average of 2.42 years later. Given that these changes in the illicit market may have increased rates of cannabis dependence in the UK, it will be important to evaluate the impact of careful regulation of cannabis potency (e.g. as planned in Uruguay) and other legislative changes (e.g. in the US) on cannabis dependence.

One explanation for our findings is that greater THC exposure enhances the dependence-forming properties of cannabis. This interpretation is in keeping with preclinical research showing that THC is reinforcing in a dose-dependent manner (Tanda et al. 2000; Justinova et al. 2003). Titration by cannabis users appears to counteract higher THC concentrations, but only partially (Freeman et al. 2014; van der Pol et al. 2014). As a result, episodic use of high-potency cannabis will typically deliver larger doses of THC.

Interestingly, people in this study added less cannabis to their joints (based on the number of joints made out of $3.5 \mathrm{~g}$ ) when using resin compared to other types. This may have further reduced their dose of THC, in addition to the low potency typical of resin. However, they took a similar number of days to smoke $3.5 \mathrm{~g}$ in total - perhaps suggesting that resin users smoke more joints with smaller amounts of cannabis (and possibly more tobacco), resulting in similar consumption of raw cannabis overall. The presence of $\mathrm{CBD}$ may also be relevant. Cannabis with a high ratio of CBD:THC (i.e. resin) reduced attentional bias to drug cues (a process implicated in addiction; Field \& Cox, 2008) relative to low CBD:THC cannabis (i.e. skunk) (Morgan et al. $2010 b)$. CBD was also found to reduce symptoms of 
cannabis withdrawal in an open-label case study (Crippa et al. 2012).

Although our results support a relationship between cannabis potency and severity of dependence, they do not imply a causal relationship, and many other factors are likely to be involved. For example, a prospective study found no independent associations between indices of cannabis use (including preferred type and THC concentrations) and subsequent incidence of dependence (van der Pol et al. 2013). This study differed from ours in a number of respects, and included a number of additional predictors (e.g. socio-demographic, vulnerability and stress factors). Additionally, it used a betweensubjects comparison of preferred cannabis type and potency as opposed to our within-subject analysis.

Contrary to our expectations, degree of cannabis use did not predict level of concerns about cannabis (memory, mental health, work or study, relationships, motivation, chronic lung disease, cancer, legal issues). This might reflect the varying susceptibility to cannabis-related harms between individuals. Another possible explanation is that more frequent users hold the belief that their use is not problematic. These findings also suggest that all levels of use can be associated with modest health concerns. This may imply that infrequent users who are not currently using treatment services are nevertheless worried about the effects of cannabis, and might benefit from help at an individual or population-based level.

It is also noteworthy that memory emerged as the strongest concern about cannabis use in this study, as this was also the most defining feature of high-potency cannabis. This is consistent with the high THC, low CBD profile of skunk. When acutely administered, THC produces robust and dose-dependent impairments in verbal memory (Curran et al. 2002; D'Souza et al. 2004) and these impairments can be ameliorated by co-administration of CBD (Morgan et al. 2010a; Englund et al. 2012). Similarly, skunk was identified as the type of cannabis most strongly associated with paranoia. This is consistent with evidence that the paranoia-inducing effects of THC can also be inhibited by CBD (Englund et al. 2012), and that regular skunk use is associated with an increased risk (Di Forti et al. 2009) and earlier onset (Di Forti et al. 2013) of psychosis, while resin/hashish is not, even in daily users (Di Forti et al. 2015).

Although skunk was most clearly defined by these negative effects, it was also rated as having the 'best high' and was considered the 'preferred type'. Clinical and public health interventions related to high-potency cannabis, focusing in its negative effects, should be interpreted in the context of users' own preferences. Given that skunk was rated as the most available type of cannabis, consistent with previous findings (Hardwick \& King, 2008; Potter et al. 2008; Freeman et al. 2014) people who do prefer it will probably find it easy to obtain in the illicit market. On the other hand, those who do not prefer skunk - or find that its negative effects outweigh the desirable ones may have little choice due to the current lack of available alternatives. Perhaps varieties of cannabis with weaker effects on memory and paranoia (e.g. other grass, resin) may be more desirable in this respect.

When comparing these lower potency varieties, it is somewhat surprising that resin was rated as having a better high and stronger effects on memory and paranoia, given that it generally contains lower THC and higher CBD than imported herbal cannabis (Hardwick \& King, 2008). It may be relevant that variation in cannabinoid content is comparatively greater in resin (Potter et al. 2008) and some resin can be highly potent (e.g. 39.3\% THC in the Netherlands; Pijlman et al. 2005). Such preparations are incredibly rare in the UK (Potter et al. 2008) but perhaps experience with especially potent forms of resin could have led some people to rate it as having the best high, and strongest effects on memory and paranoia.

This study has some limitations. First, it used a selfselecting (drug using) sample. This enabled a large number of cannabis users to be recruited, but it does limit the extent to which the findings can be attributed to the general population, or more problematic users, as dependence scores were modest on average. Second, because dependence was estimated using the SDS rather than a structured clinical interview, it was not possible to tease apart specific aspects of cannabis use disorder such as tolerance, withdrawal, craving, failing obligations, giving up other recreational interests, and persistent use in spite of problems. Additionally, the study was cross-sectional and causality cannot be established on the basis of these results. Indeed, it is quite plausible that reverse causation might explain our findings (e.g. as a result of dependence, people use more skunk). Third, skunk was used for more days per month than the other types, which might explain the reported association with dependence. However, variance in days per month of use was similar for each of the three types, suggesting that these data were equally appropriate to detect the existence of possible associations with dependence. Fourth, although we quantified use of three different cannabis preparations, we cannot be sure that the terms we used (e.g. skunk) were meaningful to the population tested (Potter \& Chatwin, 2012), although similarly named types were predictive of actual THC and CBD concentrations elsewhere (Freeman et al. 2014).

\section{Conclusion}

Use of high-potency (skunk) cannabis is associated with an increased severity of dependence, especially 
in young people. Skunk is also rated as having stronger effects on memory impairment and paranoia than other types of cannabis, but at the same time it produces the best high and is users' preferred type.

\section{Acknowledgements}

We thank all volunteers for taking part in the Global Drug Survey, Mixmag, The Guardian, and Ravi Das for their assistance, and Chandni Hindocha for her comments on an earlier version of this manuscript. We also thank two anonymous reviewers for their helpful comments and for suggesting additional analysis with age and gender. Preliminary data from this project were presented at the British Association for Psychopharmacology Summer Meeting, 2015. T. P. Freeman was supported by the Medical Research Council. Global Drug Survey is self-funded.

\section{Declaration of Interest}

A.W. is director and founder of Global Drugs Survey Ltd.

\section{References}

Coombes R (2014). Cannabis regulation: high time for change? British Medical Journal 348, g3382.

Crippa J, Hallak J, Machado-de-Sousa J, Queiroz R, Bergamaschi M, Chagas M, Zuardi A (2012). Cannabidiol for the treatment of cannabis withdrawal syndrome: a case report. Journal of Clinical Pharmacy and Therapeutics.

Curran VH, Brignell C, Fletcher S, Middleton P, Henry J (2002). Cognitive and subjective dose-response effects of acute oral $\Delta 9$-tetrahydrocannabinol (THC) in infrequent cannabis users. Psychopharmacology 164, 61-70.

Di Forti M, Marconi A, Carra E, Fraietta S, Trotta A, Bonomo M, Bianconi F, Gardner-Sood P, O'Connor J, Russo M (2015). Proportion of patients in south London with first-episode psychosis attributable to use of high potency cannabis: a case-control study. Lancet Psychiatry 2, 233-238.

Di Forti M, Morgan C, Dazzan P, Pariante C, Mondelli V, Marques TR, Handley R, Luzi S, Russo M, Paparelli A (2009). High-potency cannabis and the risk of psychosis. British Journal of Psychiatry 195, 488-491.

Di Forti M, Sallis H, Allegri F, Trotta A, Ferraro L, Stilo SA, Marconi A, La Cascia C, Marques TR, Pariante C (2013). Daily use, especially of high-potency cannabis, drives the earlier onset of psychosis in cannabis users. Schizophrenia Bulletin 40, 1509-1517.

D'Souza DC, Perry E, MacDougall L, Ammerman Y, Cooper T, Wu Y-T, Braley G, Gueorguieva R, Krystal JH (2004). The psychotomimetic effects of intravenous delta-9-tetrahydrocannabinol in healthy individuals: implications for psychosis. Neuropsychopharmacology 29, 1558-1572.
EMCDDA (2014). European Drug Report. European Monitoring Centre for Drugs and Drug Addiction.

Englund A, Morrison PD, Nottage J, Hague D, Kane F, Bonaccorso S, Stone JM, Reichenberg A, Brenneisen R, Holt D (2012). Cannabidiol inhibits THC-elicited paranoid symptoms and hippocampal-dependent memory impairment. Journal of Psychopharmacology 27, 19-27.

Field M, Cox WM (2008). Attentional bias in addictive behaviors: a review of its development, causes, and consequences. Drug and Alcohol Dependence 97, 1-20.

Freeman TP, Morgan CJ, Hindocha C, Schafer G, Das RK, Curran HV (2014). Just say 'know': how do cannabinoid concentrations influence users' estimates of cannabis potency and the amount they roll in joints? Addiction 109, 1686-1694.

Gossop M, Darke S, Griffiths P, Hando J, Powis B, Hall W, Strang J (1995). The Severity of Dependence Scale (SDS): psychometric properties of the SDS in English and Australian samples of heroin, cocaine and amphetamine users. Addiction 90, 607-614.

Hardwick S, King LA (2008). Home Office Cannabis Potency Study 2008. Home Office Scientific Development Branch: UK

Hindocha C, Freeman TP, Schafer G, Gardener C, Das RK, Morgan CJ, Curran HV (2015). Acute effects of delta-9-tetrahydrocannabinol, cannabidiol and their combination on facial emotion recognition: a randomised, double-blind, placebo-controlled study in cannabis users. European Neuropsychopharmacology 25, 325-334.

Home Office (2014). Drug Misuse: Findings from the 2013 to 2014 Crime Survey For England and Wales.

Justinova Z, Tanda G, Redhi GH, Goldberg SR (2003). Self-administration of $\Delta$-tetrahydrocannabinol (THC) by drug naive squirrel monkeys. Psychopharmacology 169, 135-140.

King LA, Carpentier C, Griffiths P (2004). EMCDDA INSIGHTS - An Overview of Cannabis Potency in Europe. Office for Official Publications of the European Communities, Luxembourg.

Morgan C, Gardener C, Schafer G, Swan S, Demarchi C, Freeman T, Warrington P, Rupasinghe I, Ramoutar A, Tan N (2012). Sub-chronic impact of cannabinoids in street cannabis on cognition, psychotic-like symptoms and psychological well-being. Psychological Medicine 42, 391-400.

Morgan CJ, Schafer G, Freeman TP, Curran HV (2010a). Impact of cannabidiol on the acute memory and psychotomimetic effects of smoked cannabis: naturalistic study. British Journal of Psychiatry 197, 285-290.

Morgan CJA, Curran HV (2008). Effects of cannabidiol on schizophrenia-like symptoms in people who use cannabis. British Journal of Psychiatry 192, 306-307.

Morgan CJA, Freeman TP, Schafer GL, Curran HV (2010b). Cannabidiol attenuates the appetitive effects of [Delta] 9-Tetrahydrocannabinol in humans smoking their chosen cannabis. Neuropsychopharmacology 35, 1879-1885.

NDTMS (2014). Adult Drug Statistics from the National Drug Treatment Monitoring System (NDTMS). Public Health England, London.

NDTMS (2015). Young People's Statistics from the National Drug Treatment Monitoring System (NDTMS). Public Health England, London. 
Pijlman F, Rigter S, Hoek J, Goldschmidt H, Niesink R (2005). Strong increase in total delta-THC in cannabis preparations sold in Dutch coffee shops. Addiction Biology 10, 171-180.

Potter DJ (2014). A review of the cultivation and processing of cannabis (Cannabis sativa L.) for production of prescription medicines in the UK. Drug Testing and Analysis 6, 31-38.

Potter DJ, Clark P, Brown MB (2008). Potency of $\Delta^{9}$-THC and other cannabinoids in cannabis in England in 2005: implications for psychoactivity and pharmacology. Journal of Forensic Sciences 53, 90-94.

Potter GR, Chatwin C (2012). The problem with 'skunk'. Drugs and Alcohol Today 12, 232-240.

Russo EB (2011). Taming THC: potential cannabis synergy and phytocannabinoid-terpenoid entourage effects. British Journal of Pharmacology 163, 1344-1364.

Swift W, Copeland J, Hall W (1998). Choosing a diagnostic cut-off for cannabis dependence. Addiction 93, 1681-1692.

Tanda G, Munzar P, Goldberg SR (2000). Self-administration behavior is maintained by the psychoactive ingredient of marijuana in squirrel monkeys. Nature neuroscience 3, 1073-1074.

UNODC (2014). World Drug Report. United Nations Office on Drugs and Crime.

van der Pol P, Liebregts N, Brunt T, Amsterdam J, Graaf R, Korf DJ, Brink W, Laar M (2014). Cross-sectional and prospective relation of cannabis potency, dosing and smoking behaviour with cannabis dependence: an ecological study. Addiction 109, 1101-1109.

van der Pol P, Liebregts N, de Graaf R, Korf DJ, van den Brink W \& van Laar M (2013). Predicting the transition from frequent cannabis use to cannabis dependence: a three-year prospective study. Drug and Alcohol Dependence 133, 352-359.

Winstock AR, Mitcheson LR, Deluca P, Davey Z, Corazza O, Schifano F (2011). Mephedrone, new kid for the chop? Addiction 106, 154-161.

Zuardi A, Shirakawa I, Finkelfarb E, Karniol I (1982). Action of cannabidiol on the anxiety and other effects produced by $\triangle 9$-THC in normal subjects. Psychopharmacology 76 , 245-250. 